\title{
Biodiversidade da raça suína autóctone portuguesa porco alentejano (Sus ibericus)
}

\author{
António R. Oliveira \\ Departamento de Biociências, Instituto Politécnico de Beja, Portugal \\ Anabela Durão \\ Departamento de Engenharia, Instituto Politécnico de Beja, Portugal \\ Fátima Carvalho \\ Departamento de Tecnologias e Ciência Aplicadas, \\ Instituto Politécnico de Beja, Portugal
}

DOI: https://doi.org/10.31492/2184-2043.RILP2018.35/pp.151-166

\begin{abstract}
Resumo
O porco Alentejano, actualmente é a raça suína autóctone portuguesa com maior efectivo pecuário e de reprodutores existentes no país. De acordo com os dados estatísticos da Direcção Geral de Alimentação e Veterinária (2017) entre as raças suínas: Alentejana, Bisara e Malhado de Alcobaça, verifica-se que a Alentejana manifesta um efectivo pecuário superior às restantes. Assim sendo, neste trabalho sobre o tema genérico biodiversidade apresenta-se apenas uma breve resenha da evolução histórica desde o registo do padrão da raça Alentejana (1959) até á actualidade. Faz-se, também uma breve descrição da "variedade mamilada" que foi recentemente inscrita no Livro Genealógico da raça suína Alentejana. Esta variedade foi objecto de um estudo de recuperação durante o século XXI, tendo-se sido confirmada a bondade reprodutiva do genótipo varrasco Alentejano Mamilado. Desde o seculo XVI, a biodiversidade das raças suínas autóctones, portuguesa e espanhola, constituem o tronco ibérico de porcos mediterrânicos.
\end{abstract}

Palavras-chave: alentejano; autóctone; biodiversidade; mamilada; porco, variedade.

\begin{abstract}
The Alentejo local pig breed is currently the Portuguese autochthonous swine breed with the highest livestock number and breeding population in the country. According to the statistical data of the General Directorate of Food and Veterinary (2017) among the swine breeds: Alentejana, Bisara and Malhado de Alcobaça, it is verified that the Alentejana shows a livestock population superior to the others. Thus, in this work on the generic biodiversity theme, we present only a brief review of the historical evolution from the registration of the pattern of the Alentejana local pig breed (1959) until today. A brief description is also given of the "mamilada variety" that was recently inscribed in the Genealogical Book of the Swine Alentejo Pattern. This variety was the subject of a recovery study during the 21 st century, and the reproductive goodness of the Alentejano Mamilado boar genotype was confirmed. Since the 16th century, the biodiversity of these Portuguese and Spanish autochthonous breeds constitute the Iberian trunk of Mediterranean pigs.
\end{abstract}

Keywords: Alentejo local pig breed; Biodiversity; Mamilada variety.

\section{Introdução}

Antes de abordarmos o tema concreto do nosso trabalho convém salientar a importância das conclusões do Congresso de Budapeste (1984), citado por Nunes 
(1985), em que a Comunidade Económica Europeia (CEE), atual União Europeia (UE), recomendou aos Estados Membros de então, as razões da defesa e conservação das suas raças locais/autóctones, pois trata-se de um direito e dever cultural, científico, zootécnico, económico e, naturalmente, uma estratégia de política social defender a fixação de populações rurais de cada Estado Membro.

O conjunto das diferentes formas de vida que existem no Planeta, como um todo, ou numa região em particular, pode ser definido como Biodiversidade. A redução drástica da biodiversidade, ou seja o desaparecimento de muitas espécies num curto intervalo de tempo é promovido pelo ser humano, com a prática intensiva de agricultura, construção de barragens, crescente urbanização, destruição das florestas entre outros factores humanos.

O montado é um ecossistema mediterrânico constituído por árvores da grande família das quercíneas [Azinheira (Quercus rotundipholia, LAM) + Sobreiro (Quercus suber, L.) de equilíbrio muito delicado, constituindo um ecossistema particular, característico sobretudo nas regiões a Sul da Península Ibérica, como é o caso do Alentejo (Portugal). O montado é um ecossistema antrópico, por isso, a sua tendência é para diminuir, conduzindo ao desequilíbrio do ecossistema (redução das espécies pecuárias, alteração dos usos do solo, nomeadamente, a transformação de áreas de sequeiro para áreas de regadio).

Como é do conhecimento o ecossistema montado foi criado pelo Homem, através da abertura do Bosque Mediterrânico e a manutenção do pastoreio e de práticas agrícolas no seu subcoberto, definindo uma paisagem peculiar no Sul da Península Ibérica. A primeira intervenção antropogénica ocorreu a 4500 a.C.. Seguiu-se um milénio de forte desflorestação e o Montado, inicia-se enquanto tal, o seu desenvolvimento, durante o período Romano, Visigodo, Árabe e Medieval, até aos nossos dias. Portanto, é um sistema antropogénico, diversificado e frágil (Oliveira, 2008a).

A montanheira, que é um sistema agro-silvo-pastoril do supracitado ecossistema mediterrânico, isto é, um regime alimentar de pastoreio, que é sazonal (Outubro a Janeiro), o que permite aos rebanhos e/ou varas de fruírem os recursos locais alimentares, tais como, bolotas, ervas de pastagem espontâneas e, no caso do porco alentejano de montanheira, ao fossar a terra, este tira melhor proveito de alguns recursos alimentares proteicos, que são considerados de baixo valor económico (ootecas, minhocas, caracóis e outros pequenos molúsculos e insectos), mas de elevado valor nutricional na sua alimentação em pastoreio directo (Oliveira, 1990; Oliveira 2000).

Assim, dentro das várias espécies pecuárias integrantes do referido ecossistema mediterrânico o porco Alentejano (Sus ibericus) é a raça autóctone que 
manifesta melhor bioeficiência no aproveitamento dos recursos locais sazonais do regime alimentar de pastoreio em montanheira.

O porco de Raça Alentejana pasta em liberdade no montado, em regime extensivo. Percorre 2 a 3 horas por dia, dezenas de quilómetros, na busca de alimentos disponíveis (bolota, pasto e proteínas de alta qualidade nutricional, molúsculos, ootecas, etc.). Na época de montanheira (Outubro a Janeiro) alimenta-se sobretudo de bolota, entre 7 a $10 \mathrm{Kg} /$ dia, proporcionando uma reposição ou aumento de ganho de peso médio diário de $1,00 \mathrm{Kg}$, até alcançar cerca de $150-170 \mathrm{Kg}$ de peso vivo por cabeça. Seu regime alimentar de pastoreio em montanheira é altamente energético e rico em gordura contendo um elevado teor de ácido oleico, do qual 60 a $63 \%$ se encontra na bolota (Freitas citado por Oliveira, 2008a).

\section{Objectivo}

O objectivo deste trabalho é dar a conhecer a biodiversidade do porco alentejano, como elemento biológico integrante do ecossistema mediterrânico montado. Assim, apresentamos uma breve descrição da resenha da evolução histórica da raça em estudo, no âmbito da estrutura taxonómica das raças suínas autóctones pertencentes ao tronco ibérico, salientando a raça suína alentejana, particularmente, a recuperação da variedade mamilada.

\section{Raça suína alentejana}

De acordo com Miranda do Vale (1949), citando Sanson (1901), sobre a origem e classificação das raças porcinas, afirma que as raças do porco Alentejano e porco Ibérico derivaram do tronco comum Ibérico, resultante da domesticação do Javali mediterrânico, mais propriamente da espécie Sus mediterraneus, sub-género Mediterraneus, forma intermediária dos sub-géneros Striatosus e Scrofa.

As duas raças, porco Alentejano e porco Ibérico, têm o seu habitat na Península Ibérica (pastagem arborizada) em regiões confluentes, nomeadamente, o primeiro na região do Alentejo, distritos de Portalegre, Évora e Beja e o segundo em Castela-Leão, Castela-a-Mancha, Andaluzia Ocidental e na quase totalidade da Extremadura Espanhola.

As razões que levaram à quase extinção da exploração extensiva do porco na Península Ibérica. No que se refere ao porco Ibérico, sabemos que foi Odriozola em 1944-1945, conforme referência de Rodrigañez et al. (1998a; 1998b), que reiniciou a exploração do porco Ibérico na propriedade estatal Dehesón del Encinar, situada em Toledo. Odriozola (1976), efectuou cruzamentos e selecção entre quatro das linhas existentes, nomeadamente, duas Portuguesas (Ervideira e Caldeira) e duas Espanholas, negros lampinhos (Campanario e Puebla). 
A Asociación Española de Criadores de Ganado Porcino Selecto Ibérico Puro y Tronco Ibérico (AECERIBER) (Diéguez, 1992, 1999 e 2000), reconheceu como variedades de porco Ibérico as seguintes: (1) Negro Estremenho (Silvela, Villalón, Oliventino, Censyra y Valdesequera); (2) Negro Português (Caldeira-Avermelhada ou Preta e Ervideira-Ruiva com pelagem sempre escura); (3) Lampinho Espanhol (del Guadiana o Guadyerbas - Puebla, de la Serena-Campanario); (4) Lampinho Português com extremidades mais finas; (5) Ruivo (Retinto Extremeño, Lampiño del Guadiana de los años 40-50 Entrepelado); (6) Torbiscal que resultou do cruzamento entre as linhas (Lineas Portuguesas Caldeira y Ervideira e Lineas Españolas Lampiño del Guadaina o Guadyerbas y Lampiño de la Serena = Vetado Pezuñas, linea de selección en la actualidad para produción de magro); (7) Mamilado (Linea Cerrada Escasa - Variedad de Estirpe Retinto Censo muy reducido); (8) Dourado de Cádiz (Dorado Gaditano - Linea Cerrada Escasa) e (9) Malhado de Jabugo cruzamento entre as linhas (Razas Ibéricas Rubios y Retintos e Berkshire y Large White). Embora, a AECERIBER aceite os cruzamentos do porco Ibérico com Large Black e de porco Ibérico com Duroc Jersey a 50 e $75 \%$, respectivamente, pelo seu significado produtivo, considera que tais cruzamentos provocam uma dispersão genética na 2. ' geração (F2), que impede a normalização dos animais e dos produtos deles obtidos.

Quanto à área de distribuição geográfica do porco de tronco ibérico (zonas de azinheira e do sobreiro, temos: Sudoeste de Espanha, Alentejo e zona serrana algarvia e nos distritos de Castelo Branco, Santarém e Setúbal. (Pires da Costa, 1988).

Em relação ao porco Alentejano, segundo Miranda do Vale (1949) e Frazão (1965) as três principais linhas ou variedades são a Preta ou Caldeira, a Ruiva ou Ervideira e a Aloirada. Esta última variedade considerada descendente directa do porco Ibérico ancestral, bem como a variedade mamilada, ambas foram dadas como extintas, embora haja exemplares em algumas explorações pecuárias, não dispomos ainda do número de efectivos existentes no país.

Verifica-se que há uma grande interacção entre as duas raças, porco Alentejano e porco Ibérico, embora o primeiro só há algum tempo esteja a ser objecto de estudo mais metódico e aprofundado. No entanto, data de 1959 a definição do Padrão da Raça (Ministério da Agricultura e da Economia, 1959), conforme a Portaria n. ${ }^{\circ} 17133$ de 22 de abril de 1959, constante do Anexo I.

\subsection{Evolução Histórica da Raça}

Consta que foram os Visigodos que desenvolveram a criação de porcos no Alentejo (Balabanian, 1980) e que os Árabes iniciaram a conversão da floresta 
em montado (Matoso \& Sousa, 1997), sendo referenciada por Cronistas Gregos a engorda de porcos feita por povos que outrora habitaram a Península Ibérica (Andrade, 1938 e Póvoas Janeiro, 1944).

Nos séculos XII e XIII a colonização da Península pelos cristãos promoveu um avanço considerável na produção do porco utilizado como base alimentar (Boisselier, 1999). Em simultâneo estabeleceram-se em definitivo os conceitos de montado e o binómio porco/montado, constantes das cartas Forais de Évora, 1166 e de Beja, 1254 (Moniz, 1995).

O primeiro dado quantitativo de porco Alentejano é de 1852 e aponta um total de 206.667 cabeças, embora se deva a Carlos Bonnet (1849), o primeiro censo (Andrade, 1938). Em 1870 o Recenseamento Geral dos Gados no Reino de Portugal, apurou um total de 207234 cabeças de suínos o que levaria a pensar em algum abaixamento da produção. No entanto, Miranda do Vale (1949), refere que deveriam existir 257041 cabeças, uma vez que é admitido que $25 \%$ do efectivo não tenha sido recenseada.

A criação e a engorda de suínos adquiriram, ao longo do século XIX e na primeira metade do século XX grande importância em termos de exploração pecuária, sendo até referido que nenhuma outra raça aproveitava tão bem os excedentes do montado (Machado, 1870, cit. por Freitas, 1998).

No século XX, verifica-se que muitas famílias Alentejanas criam o seu porco para a matança caseira e na década de quarenta, para além da exploração de outras espécies pecuárias, a criação do porco Alentejano, adquiriu uma importância notória na economia agro-pecuária na região Sul do País (Bettencourt, 1945; Miranda do Vale, 1934), representando uma fonte alimentar de carne fresca e salgada, associada ao pão de trigo e à azeitona, ingredientes fundamentais da alimentação da população Alentejana (Autores Vacas e Ribeiro, ambos, citados por Freitas, 1998).

Segundo o Boletim do Arrolamento Geral de Gado em 1955, o efectivo suíno nas três regiões Alentejanas (Beja, Évora e Portalegre), era de 399.458, sendo o porco Alentejano a população suína mais homogénea do País e correspondente a cerca de $45 \%$ do efectivo existente em Portugal Continental (Carvalho, 1964).

Após a II Guerra Mundial, assistiu-se ao declínio da raça suína autóctone Alentejana, que perde a sua importância económica e industrial (Simões, 1964) devido a vários factores de que se salienta: alterações nos hábitos alimentares das populações, em geral, que passam a preferir carnes cada vez mais magras, o aparecimento dos primeiros focos da Peste Suína Africana em Portugal em 1957 e o seu ressurgimento mais tarde em 1960 (Braço-Forte \& Mendes, 1964), cruzamento indiscriminado das raças suínas exóticas selectas com a raça autóctone, mudanças na política agrária e no sistema de exploração com encurtamento do 
ciclo de produção devido à utilização de raças suínas selectas, perda de rendibilidade da montanheira devido à elevação do custo de mão-de-obra e ausência de limpeza das árvores e arroteamento dos montados.

Em consequência, fomentou-se a substituição do porco Alentejano (Pimentel, 1977) apoiando o cruzamento de varrascos Landrace com a porca Alentejana (Frazão, 1984), visando melhores relações carne/gordura na carcaça no então chamado porco Alentejano Melhorado (Frazão, 1984).

As razões atrás apontadas para o declínio da produção do porco Alentejano associadas ao desinteresse da indústria de salsicharia pela carne deste tipo de porco, motivada pela baixa relação carne/gordura na carcaça, a rejeição do consumo da gordura animal pela população, face à divulgação dos benefícios das gorduras vegetais, a morosidade da produção de um porco de tipo gordo (Frazão, 1965), conduziram à apresentação do relatório sobre o plano de Melhoramento Animal em 1967, em que se defendia claramente, que a produção suína nacional se devia orientar para a produção de porcos de tipo precoce. Assim sendo, a produção do porco Alentejano estaria definitivamente comprometida (Freitas, 1998).

Além disto, o abaixamento da produção do porco Alentejano foi agravado pela medida adoptada pelo Governo de então em instituir uma linha de crédito para financiamento agro-pecuário abrangendo a construção, ampliação e remodelação de núcleos de exploração suinícolas, em ciclo fechado (Perestrelo-Vieira \& Silveira-Ramos, 1985).

Na década de oitenta, Frazão (1984), chamou a atenção para o perigo de extinção do porco Alentejano, visto que nas explorações ainda existentes eram feitos cruzamentos de forma indiscriminada para fins industriais e para venda de leitões ao desmame (Bettencourt, 1984).

Nestas condições a falta de identificação dos animais dos pequenos núcleos, que se mantiveram fechados e isolados com baixa taxa de substituição de reprodutores levaria provavelmente ao aparecimento de efeitos nefastos pela elevada taxa de consanguinidade entre e dentro dos referidos núcleos (Antunes-Correia \& Oliveira, 1985; Antunes-Correia, 1989).

Apesar da insistência de alguns autores (Nunes, 1993; Oliveira, 1990), para a importância da produção e interesse do porco Alentejano, como raça suína autóctone a defender, no final da década de oitenta não havia qualquer enquadramento legal que a protegesse. Só em 1992 foi regulamentado o Programa Específico do Porco Alentejano de Montanheira no contexto do Programa Nacional de Apoio à Restruturação e Inovação do Sector Agrícola - Programa NOVAGRI (Ministério da Agricultura, 1992). Mais tarde, através das Portaria n. ${ }^{\circ} 809-\mathrm{C} / 94$ e n. ${ }^{\circ}$ 980/95 (Ministério da Agricultura, 1994 e 1995) foi o Programa de Apoio à Modernização 
Agrícola e Florestal (PAMAF) e as medidas Agro-Ambientais que promoveram a reintegração do porco Alentejano no seu habitat natural do montado.

A União das Associações de Criadores do Porco Raça Alentejana (UNIAPRA), que foi fundada em 1993, que integra a Associação de Criadores do Porco Raça Alentejana (ACPA) e a Associação Nacional de Criadores do Porco Raça Alentejana (ANCPA). A UNIAPRA foi detentora do Livro Genealógico Português de Suínos - Secção Raça Alentejana (LGPS-SRA) e controlou a fileira emergente do porco Alentejano.

Em relação aos censos de efectivos pecuários efectuados, até ao ano 1985, registou-se um total de 4947 cabeças de animais reprodutores (Antunes Correia \& Oliveira, 1985 e 1986; Oliveira, 1990 e 2000), o que despertou a atenção das Entidades Oficiais Portuguesas, para a raça em estudo. A partir de 1995 o efectivo começou a crescer até ao momento do desencadeamento da crise económica e financeira internacional 2007-2008. Tal promoveu impactos no mundo agrário e, naturalmente, na fileira emergente do porco Alentejano (Oliveira, 2011).

Para as campanhas de comercialização (vendas de porcos alentejanos) em Portugal e Espanha, respectivamente para 2007-2008 e 2008-2009 (Oliveira, 2011) as Associações de Criadores de Porco Alentejano (ACPA e ANCPA), apresentam no conjunto um saldo positivo de ( +3372 cabeças), no total de cabeças de porcos abatidos e comercializados.

De salientar que a crise económica e financeira global, que se manifestou desde 2007-2008 continua a fazer-se sentir nos diversos sectores da fileira emergente da raça, apesar do número de cabeças aumentar da campanha de 2007-2008 para a de 2008-2009. No ano transacto o preço por Kg de carcaça à produção era aproximadamente 3,00 euros, mas actualmente é, em média, de 2,35 euros (Oliveira, 2011).

Portanto, os produtores estão, a sofrer prejuízos com um agravamento do preço à produção da ordem de 0,65 euros $(21,7 \%)$ por Kg de carcaça o que provoca a retracção do mercado, tanto em Portugal como em Espanha, cujo preço de porco ibérico baixou mais de $50 \%$ e o preço dos presuntos mais de $40 \%$, pelo que o sector atravessa uma situação crítica e insustentável, ameaçando a própria subsistência do montado como ecossistema, segundo a Associação Espanhola (ASICI, 2009).

No início do século XXI, efectivamente, a tendência para um crescimento exponencial de registo dos reprodutores inscritos activos e que se verifica até ano de 2007/08 (Oliveira, 2008a). A partir desta altura, como é do conhecimento, a crise económica e financeira mundial começou a manifestar-se na Europa, Portugal e Alentejo. Assim sendo, o efectivo pecuário e os produtores da raça em 
estudo diminuíram até atingirem os valores 6625 cabeças de reprodutores activos inscritos.

Portanto, a situação do porco alentejano em 2007 (Oliveira, 2011), havia um aumento de registo de reprodutores e de acordo com as recomendações contidas no Relatório da FAO, DAD-IS (Interlaken, 2007), manter a biodiversidade possível apoiando os produtores com um subsídio pecuniário, por cabeça, em raça pura, exploração in situ. Esta tarefa foi levada a cabo pelo Ministério da Agricultura através da Direcção Geral de Veterinária (DGV) - Plano de Desenvolvimento Rural, estratégias para conservação e melhoramento das raças autóctones (2007-2013), estipulando um apoio de efectivo nacional de Fêmeas exploradas em linha pura, inscritas no Livro Genealógico de Adultos, sendo um total 10000 cabeças, de suínos de raça alentejana, referidas no Relatório de 2006 da Direcção dos Serviços de Produção Animal da Direcção Geral de Veterinária (Oliveira, 2011).

Pela análise e comparação dos dados e resultados estatísticos de 2013 (Oliveira et al., 2014) com os dados e resultados actuais do Agrupamento Complementar de Empresas do Porco Alentejano A.C.E. (ACEPA), gentilmente cedidos pela Associação de Criadores de Porco Alentejano (ACPA, 2016), verifica-se que actualmente há um aumento percentual no número de porcas activas inscritas no Livro de Adul-

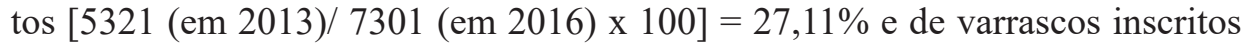
no Livro de Adultos [316 (em 2013)/ 471 (em 2016) x 100] = 32,91\%, bem como de explorações inscritas no Livro Genealógico do Porco Alentejano (LGPA) (Oliveira, 2017).

\subsection{Variedade Mamilada}

A variedade mamilada portuguesa (Fig. 1) caracteriza-se: pela cor da pele preta ardósia ou ruiva, com cerdas pretas ou ruivas, curtas, finas e escassas em toda a superfície do corpo; com cabeça e orelhas de tamanho médio, dirigidas para frente e com as pontas triangulares viradas ligeiramente para cima; ângulo frontonasal pronunciado e focinho pontiagudo; pescoço bem ligado ao corpo e, por vezes, com pregas na pele; papada pouco pronunciada e com mamilos uni- ou bilateral (característica da variedade); tórax com costelas arqueadas e musculadas e abdómen com desenvolvimento normal; região dorsal retilínea e lombo descaído com inserção média-baixa da cauda; membros com extremidades finas e unhas pretas e rijas; temperamento vivaço; verdadeiros trepadores dado que são muito equilibrados de aprumos e podem percorrer longas distâncias em terrenos acidentados e zonas de serra (Oliveira \& Nobre, 2011). O varrasco mamilado (Fig. 2) manifesta "bondade reprodutiva" ou seja fertilidade, fecundidade com 
aumento do número de leitões/porca/parto/e ao desmame, passando de 6,5 para 7,4 por porca/parto/desmame (Oliveira, 2012) em relação às outras variedades, quando acasalado com porcas reprodutoras não mamiladas (Oliveira, 2010b; Oliveira 2012).

Figura 1. Porcas Alentejanas mamiladas e não mamiladas (Oliveira, 2011).

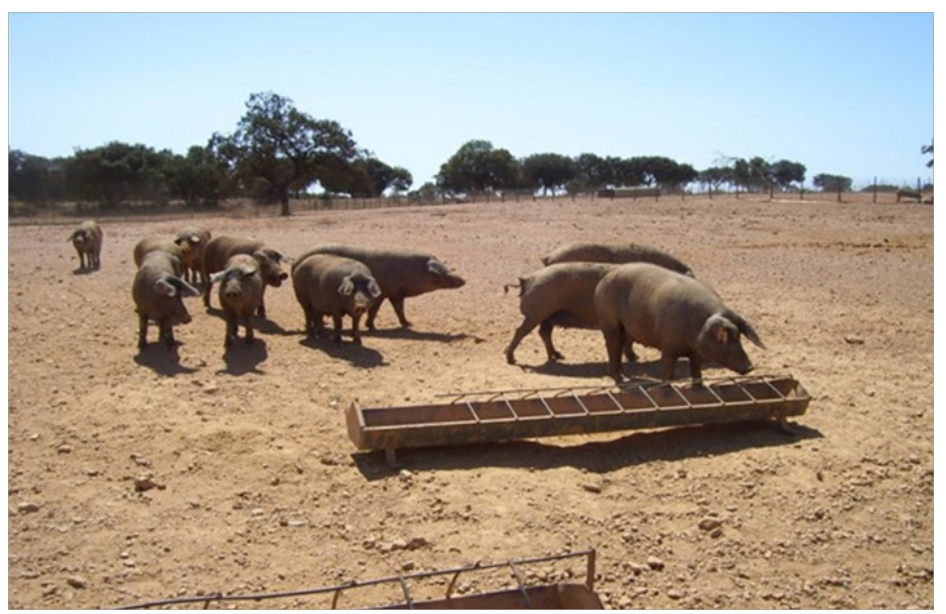

Os genótipos (machos e fêmeas não mamilados) já estão registados, através de imagens de fotos no DAD-IS da FAO desde 2002-2003 (Oliveira, 2011). Apesar de existir um Banco de Germoplasma Animal, que abrange todas as raças autóctones nacionais (Gama, 2010), para as espécies suínas não mamiladas tal não se verifica. Quanto á preservação das raças suínas autóctones é difícil ou inexistente, pois tal se deve aos problemas de natureza biotécnica, que estão intrinsecamente ligados ao processo de criopreservação do sémen dos suínos (Sancho et al., 2007; Cardoso et al., 2013; Zasiadczyk et al., 2015; Guimarães et al., 2018).

Os métodos de conservação e recomendados por Sieuve Monteiro, citado por Oliveira (1990) dos recursos genéticos animais são: (1) manutenção das populações animais; (2) tecnologia de congelação do sémen e (3) tecnologia de congelação de embriões.

Assim, no Instituto Politécnico de Beja/ escola Superior Agrária (IPBeja/ESA) optamos por exploração in situ na conservação de porcos alentejanos, utilizando o principal método de conservação de recursos genéticos animais (manutenção das populações animais).

A variedade mamilada, é aquela que manifesta a existência de mamilos uni ou bi lateral localizados na região do pescoço (Fig. 2), tendo sido recuperado no IPBeja/ ESA. O efeito dos mamilos aumenta a produtividade numérica $(\mathrm{Pn})$ das porcas, efeito pleiotrópico (Clemente et al. 2006), o que significa um real aumento natural 
de número de leitões por porca/parto. Tal, contribui naturalmente, para a conservação e biodiversidade deste património genético autóctone in situ e quiçá ex situ. Este último método de conservação, carece de ensaio experimental.

Figura 2. Varrasco Alentejano mamilado (Oliveira, 2011).

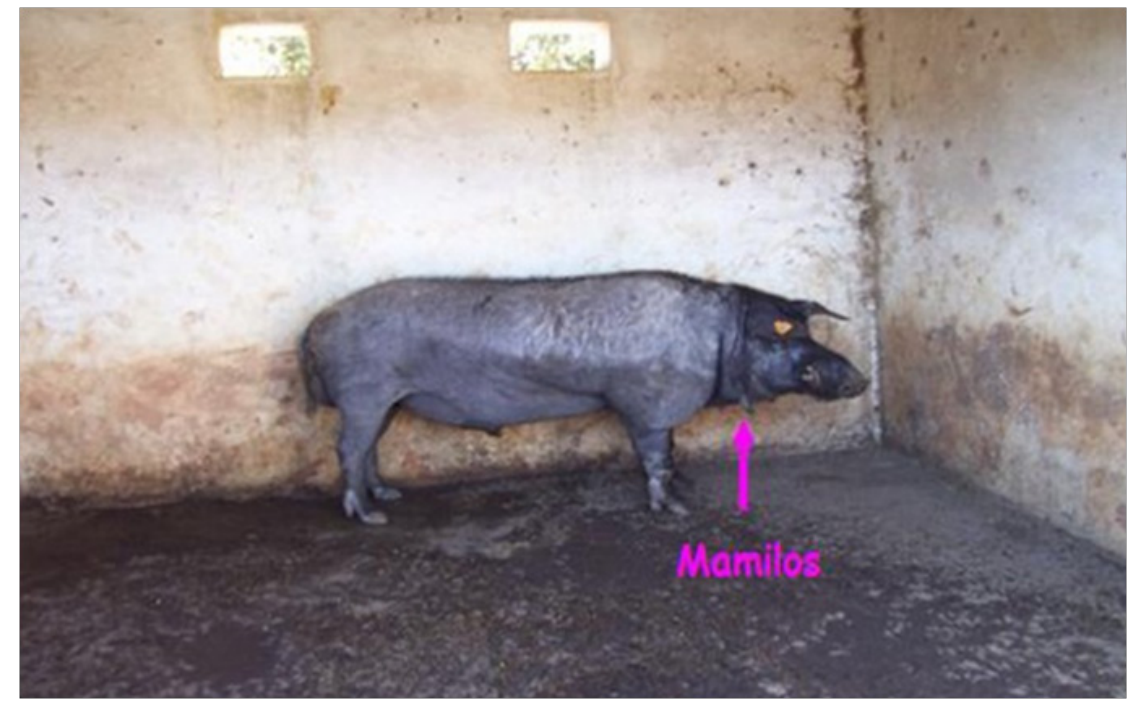

As áreas estratégicas prioritárias no Plano Global de Acção: (1) caracterização, inventário e monitorização de tendências e riscos associados; (2) utilização e desenvolvimento sustentável; (3) conservação; e (4) políticas, institucionais e melhoria da capacidade, aprovadas no Congresso de Interlaken (2007). A sua finalidade foi promover a conservação e sustentabilidade das raças autóctones. A recomendação para Portugal incidiu sobre a criação de Banco de Germoplasma Animal (BPGA, 2010), bem como a elaboração e aprovação do Regulamento de Funcionamento do referido Banco, publicado a 08-06-2016.

O IPBeja/ESA manteve a exploração de porcos Alentejanos in situ de 1993/94 a 2011/12, período durante o qual procedemos aos ensaios experimentais na exploração in situ. Entre 2005 e 2009, recuperamos a variedade mamilada, embora continue em vias de extinção, por outro lado, confirmamos a bondade reprodutiva do varrasco mamilado.

As dificuldades verificadas relativas ao processo de criopreservação e a aplicação das recomendações do Congresso de Interlaken (2007), particularmente para as raças suínas autóctones, não é uma tarefa fácil, pelo que continuamos, actualmente, a defender a manutenção das populações animais, in situ. Por outro lado, aguardamos que os investigadores possam obter resultados mais credíveis na aplicação da metodologia de criopreservação do sémen de suínos. De acordo 
Lino Neto (2017) a tecnologia de congelação de embriões de suínos alentejanos é viável.

Os dados estatísticos sobre o efectivo pecuário da variedade mamilada são escassos e/ou inexistentes em Portugal, sendo provável que esta variedade esteja também ameaçada e, em perigo de extinção, tal como referido por FAO REPORT, 1992, 2002; Gama 2002; FAO REPORT, 2006, citado por Clemente et al. (2006), para o porco mamilado ibérico.

Segundo Gama (2008), as recomendações de Portugal de acordo com o referido no Congresso de Interlaken, (2007) são: os países representados reconhecem a soberania nacional sobre os respectivos recursos genéticos animais; manifestam a sua preocupação quanto à erosão observada a nível mundial; assumem o compromisso de trabalhar no sentido de ser conseguido o uso sustentável, desenvolvimento e conservação desses mesmos recursos.

A Sociedade Portuguesa de Recursos Genéticos Animais (SPREGA), fundada em 2002, sem fins lucrativos, alerta os responsáveis das entidades oficiais portuguesas, para os perigos de extinção de cada uma das raças autóctones nacionais, tendo em conta o valor científico, cultural e social, bem como a valorização do seus produtos finais, que são de qualidade certificada, isto é, são produtos de valor acrescentado e transacionáveis.

Face ao exposto e, pela definição do conceito de biodiversidade, verificamos que foi acrescentado alguma evolução no Padrão da Raça Autóctone Porco Alentejano, mas apenas para registar uma variedade recuperada (Variedade Mamilada - Anexo II) descrita por Oliveira \& Nobre, (2011), aceite pelo Regulamento do Livro Genealógico do Porco Alentejano (LGPA), cuja versão final foi publicada em 28-04-2014.

\section{Comentários e sugestões}

A biodiversidade, entre e dentro dos genótipos da raça em estudo, é fundamental para evolução e adaptação ao seu natural ecossistema mediterrânico montado, não descurando os impactos ambientais provocados pelas alterações climáticas, que poderão ter no geral e, em particular, o efeito da rarefacção reprodutiva, pondo em causa uma evolução positiva dos diversos tipos de genótipos que integram o padrão da raça em estudo.

Devido a inexistência de levantamentos do efectivo da variedade da raça suína alentejana mamilada (reprodutores), propõe-se para trabalhos científicos futuros a realização destas tarefas ligadas ao seu estudo devidamente sistematizado. Pois, a ausência de dados credíveis, dificulta o conhecimento, por exemplo, da produtividade numérica (Pn), isto é, o número de leitões desmamados por porca por parto 
e não só, mas também corremos o risco de provocar a extinção da variedade, sem possibilidade de recuperação da mesma, por ser demasiada onerosa a implementação de projectos de investigação, para recuperar e preservar simultaneamente o genótipo em perigo, embora a bioinformática, no contexto das ciências ómicas apresentam soluções inovadoras (Ruiz \& Herrero, 2015), embora bastante onerosas.

Assim, ao fim de 50 (cinquenta) anos (1959-2009) de registo do padrão da raça suína alentejana, verifica-se que apenas subsiste na raça a mistura entre e dentro das variedades e/ou linhas tradicionais (caldeira, ervideira e aloirada), embora a variedade mamilada continua em número reduzido, isto é, em perigo de extinção (Gama, 2002; FAO-REPORT, 2006). Assim sendo, recomendamos a preservação in situ do património genético natural e cultural da Raça Autóctone Porco Alentejano (Sus ibericus), tendo em conta a genuinidade e a qualidade nutricional, organoléptica e dietética dos produtos finais, não descurando o efeito da potenciação do combate às doenças cardiovasculares e aterogénicas para os consumidores, enquanto alimento saudável, passível de integrar o grupo dos alimentos Gourmet no contexto da roda dos alimentos proposto para a da dieta mediterrânica (Oliveira et al., 2013).

O Binómio Porco Alentejano / Ecossistema Montado é uma das fontes da biodiversidade, base do desenvolvimento sustentável da fileira emergente desta raça suína autóctone com maior efectivo pecuário nacional, cuja genuinidade dos seus produtos finais urge manter (Oliveira, 2008a).

Embora, o efectivo pecuário da raça autóctone em estudo tem vindo a sofrer o efeito devastador pela acção da crise económica e financeira mundial com início em 2007-2008, mesmo assim, ainda mantem o número de cabeças do efetivo ligeiramente superior ao recomendado pela FAO (Oliveira et al, 2014), para preservação de raças suínas autóctones, evitando assim o risco de se encontrarem em vias e/ou em perigo de extinção, embora a ameaça seja evidente, recomenda-se a exploração in situ, evitando atingir o limiar crítico de extinção de acordo com as indicações da FAO.

Assim, urge defender não só a raça, mas também por razões científicas, técnicas e culturais em defesa do ecossistema montado, por um lado a promoção do mundo rural e a sua paisagem, facilitando a fixação de populações em meios rurais, promovendo o desenvolvimento e a inovação, particularmente, por outro lado a obtenção e comercialização dos produtos finais de qualidade certificada e/ ou de valor acrescentado, com impacto para a nutrição, alimentação e saúde do consumidor (Oliveira et al., 2013).

Para terminar, não descurando a publicação do relatório (2014-2017) do Gabinete Politicas Públicas (GPP), conforme Decreto Lei n 95/2014 (referência 
"porco preto"), diferente de porco alentejano, para fins de comercialização, pelo que continuamos a aguardar a publicitação do mesmo. Assim sendo, a recomendação fundamental, para o futuro, é criar uma plataforma digital de registo para controlo dos acasalamentos controlados, independentemente do reprodutor utilizado, tendo em conta sempre o padrão característico da raça descrita desde 1959. Pois, como é do conhecimento, que as linhas e variedades dos genótipos reconhecidos e registados através do Regulamento do Livro Genealógico da Raça, estão mais que adaptadas ao milenar ecossistema mediterrânico do montado.

\section{Conclusão}

Apesar da variabilidade da raça autóctone em estudo ser evidente, entre e dentro das linhas e variedades conhecidas e recuperadas, ainda permanecem entre os genótipos existentes (não mamilados e mamilados, estes últimos em número muito escasso), explorados pelos produtores do porco alentejano, há manifestação de fenómenos genéticos de atavismo, endogamia, sex-ratio, pleiotropia, deriva genética, pois trata-se de populações animais pequenas, isoladas e fechadas.

Estes fenómenos genéticos supramencionados podem contribuir para reduzir ou inviabilizar a manutenção da variabilidade da raça autóctone porco alentejano, pois podem manifestar-se em qualquer espécie de ser vivo, particularmente, em espécies pecuárias de raças autóctones, razão pela qual a aplicação dum plano de melhoramento genético para raças autóctones deve começar pela conservação in situ visando manter e/ou ampliar a biodiversidade das mesmas, não descurando o seu padrão racial característico, evitando a todo o custo atingir o limiar critico de extinção recomendado pela FAO.

\section{Agradecimentos}

Agradecemos a colaboração das Associações de Criadores do Porco Alentejano, pela gentileza de nos terem facultado alguns dados e resultados, sobre a raça autóctone portuguesa em estudo.

\section{Referências}

Antunes-Correia, J., \& Oliveira, A. (1985). Evolução da consanguinidade em núcleos fechados de

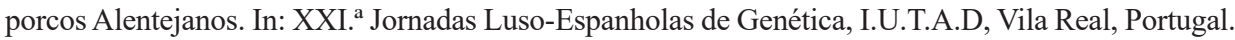

Antunes-Correia, J. (1989). Análise da evolução da consanguinidade em núcleos de porcos Alentejanos. Implicações de algumas práticas zootécnicas sobre os seus níveis. In: Anais da Faculdade de Medicina Veterinária de Lisboa, Vols. XXXV/XXXVI:107-119.

Balabanian, M. (1996). Variación de la composición en ácidos grasos de cerdos ibéricos alimentados en montanera. Tesina de Licenciatura. UEX, Cáceres. 
Bettencourt, J. (1984). Salsicharia do Porco Alentejano. In: I. ${ }^{a}$ s Jornadas Luso-Espanholas del Cerdo Iberico, 14, 15 e 16 de Maio. Colégio de Veterinários, Badajoz, Espanha. Trabalho policopiado.

Boisselier, S. (1999). Naissance d'une Identitté Portuguaise.La vie rurale entre Tage et Guadiana de L'Islam ala Reconquête (Xe-XIVe Siècles). Estudos Gerais Série Universitária, Editado pela Imprensa Nacional Casa da Moeda, Lisboa, pp.7-707

Braço-Forte, M., \& Mendes, A. (1964). Aspectos actuais da patologia porcina em Portugal. Revista de Ciências Veterinárias, 288:45-53

Cardoso, T., Varela Junior, A., Silva, E., Gheller, S., Silva, A., \& Dahlcorcini, C. (2013). Criopreservação de sémen de suíno: alternativas para optimização da técnica. Ciência Animal 23(2):03-15.

Clemente, I., Membrillo, A., Azor, P., Dorado, G., Rodero, A. \& Molina, A. (2006). Algunas consideraciones sobre as diferentes clasificaciones del tronco porcino ibérico: una propuesta integradora. Revista Solo Cerdo ibérico, 16:7-18.

Diéguez, G. (1992). Evolución y situación actual del cerdo Ibérico. In: El Cerdo Ibérico, la Naturaleza, la Dehesa. Simposio de cerdo Ibérico, Zafra, 30 de Septiembre y 1 de Octubre. Ed. Ministério de Agricultura, Pesca y Alimentación. Secretaria General Técnica, España, pp.11-35.

Diéguez, G. (1999). La raza porcina Ibérica: sus estirpes y selección. In: I Jornadas sobre el Cerdo Ibérico y sus Productos, Salamanca-Guijuelo, 22-25 de Junio. Edita: Estación Tecnológica de la Carne de Castilla y Léon. Consejeria de Agricultura y Ganaderia .Junta Castilla y Léon, pp.21-28.

Diéguez, G. (2000). A raça e o seu sistema produtivo. In: Colóquios Técnicos da 17:a Ovibeja/2000.

FAO (2002-2003). DAD-IS - Domestic Animal Diversity Information.

FAO Report. (1992). Expert Consultation on the Management of Global Animal Genetics Resources. Rome.

FAO Report. (2002). Expert Consultation on the Management of Global Animal Genetics Resources. Rome.

FAO Report. (2006). Congresso Nacional de Zootecnia 25 e 26 de Octubre.

Frazão, T.L. (1965). O porco Alentejano. Ministério Agricultura Pescas e Alimentaçäo. Boletim Pecuário, 33 (4):5-33.

Freitas, A. (1998). Influência do nível de regime alimentar em pré-acabamento sobre o crescimento e desenvolvimento do porco Alentejano e suas repercursões sobre o acabamento em montanheira e com alimento comercial. Tese de Doutoramento. Universidade de Évora. 305 pp.

Gama, L. (2002). Melhoramento Genético Animal. Escolar Editora, Lisboa, Porto, 306 pp. ISBN 972-592-151-8

Gama, L. (2008). Forum troca de informações. Newsletter Veterinária Actual.

Guimarães, D., Barros, T., Cantanhêde, L., Feugang, J., Leonardo Peres de Souza, L., \& Toniolli, R. (2018). Qualidade espermática durante a curva de resfriamento do sémen suíno diluído em água de coco em pó visando a sua criopreservação. Cienc. Anim. Bras., Goiânia, v.19, 1-16, e-38250, 2018. DOI:10.1590/1809-6891v19e-38250. 
Interlaken. (2007). Global Plan of Action for animal genetic resources and the Interlaken declaration. International Technical Conference on Animal Genetic Resources for Food and Agriculture Interlaken, Switzerland, 3-7 September 2007.

Lino Neto, R. (2017). Comunicação oral .34. ${ }^{a}$ Ovibeja'2017, Beja

Matoso, J., \& Sousa, A. (1997). Degradação do coberto vegetal. In: Historia de Portugal, Segundo Volume Ed. Editorial Estampa, Lisboa., pp.271-275

Ministério da Agricultura e da Economia. (1959). Padrão da Raça Suína Alentejana. Diário da República. Portaria n. ${ }^{\circ} 17133$ de 1959.04.22

Moniz, M. (1995). O Porco na história Baixo-Medieval de Évora. Cadernos de Etnográfia n. ${ }^{\circ}$ 2, Edição da Câmara Municipal de Évora, Évora

Nunes, J. (1985). A raça suína alentejana. In: I Congresso sobre o Alentejo. Realizado em Évora, 25 a 27 de Outubro de 1985, 3p. Policopiadas.

Nunes, J. (1993). Contributo para a reintegração do porco Alentejano no montado. Tese de Doutoramento. Universidade de Évora. 276 pp.

Odriozola, M. (1976). Investigación sobe los datos acumulados en dos piaras experimentales. IRYDA. Madrid.

Oliveira, A. (1990). Estudo de Alguns Parâmetros produtivos do Porco Alentejano com vista à obtenção de produtos de salsicharia tradicional (Presunto). Tese de Mestrado em Produção Animal. INIA/EZN-UTL/FMV, Lisboa, 125 pp.

Oliveira, A. (2000). Estudio de las Características de la Canal y de la Grasa del Cerdo Alentejano (Sus ibericus).Tesis Doctoral. Universidad de Extremadura. Facultad Veterinaria, Cáceres, 168 pp.

Oliveira, A. (2008a). Potencialidades do Binómio Porco Alentejano / Ecossistema Montado. Comunicação Oral por Convite. Colóquio "Reflexões sobre o Porco Alentejano e Montanheira". In: II Jornadas Gastronómicas Sabores do Porco Alentejano, Ourique.

Oliveira, A. (2010b). Alentejo Pig Breed Nipple (Sus ibericus). Preliminar Scientific Nótula (I). In: Abstract Book 7.th. International Symposium on Mediterranean Pig Organized by Faculty of Agricultural and Forestry Engineering. University of Cordoba, 14, 15 y 16 October, Session 1 Genetics, p.19

Oliveira, A., \& Nobre, J. (2011). Raça Suína Autóctone Portuguesa. Características Específicas da Variedade Mamilada da Raça Suína Alentejana. Revista Suinicultura da Federação Portuguesa de Associações de Suinicultores, FPAS, 90:42

Oliveira, A. (2011). Nótula Histórica sobre Porco Alentejano (Sus ibericus), 1. Edição, Edição do Autor: Portugal.

Oliveira, A. (2012). Alentejo Pig Breed Nipple (Sus ibericus). Preliminar Scientific Nótula (I). In: 7th. International Symposium on the Mediterranean Pig. Proceeding Options Méditerranéennes, SERIE A: Mediterranean Seminars n. ${ }^{\circ}$ 101:93-96

Oliveira, A., Regato, M., Baer, I., Carvalho, M., \& Valente, M. (2013). Qualidade de matérias-primas agro-alimentares alentejanas qualificadas com valor acrescentado. In: VII Congresso Mundial do Presunto, Ourique 28 a 31 de maio de 2013, 6pp. www.ourique2013.com 
Oliveira, A., Faustino, N., Duarte, F., Camacho, P., Guerreiro, L., Martins, F., Bento, P., \& Guerreiro da Silva, P. (2014). Fileira emergente do porco alentejano no contexto da agricultura familiar e desenvolvimento sustentável entre a tradição, dieta mediterrânica e inovação. In: ATAS Proceedings of 20th. APDR Congress, 2014 July 10-11 "Renaisance of the Regions of Southern Europe, University of Evora, Évora, pp.481-493, ISBN 978-989-8780-01-0.

Oliveira, A. (2017). Raça Suína Autóctone Portuguesa Porco Alentejano (Sus ibericu). Lição proferida no âmbito de provas públicas para Professor Coordenador. IPBeja-ESA, Beja, 18 de Setembro de 2017.

Perestrelo-Vieira, R., \& Silveira-Ramos, M. (1985). O Porco Alentejano. Limitantes sanitárias do seu modo de exploração. Revista O Suinicultor, 1(6):10-27.

Pimentel, M. (1977). Classificação de carcaças de suínos. In: Colóquios Agropecuários. FILAGRO 77, Edição Junta Nacional de Produtos Pecuários, Lisboa.

Pires da Costa, J. (1988). A Suinicultura em Portugal (II). Rev. Vida Rural,1452, 35 (7/88):18-21.

Rodrigañez, J., Toro, M., Rodríguez, C., \& Silió, L. (1998a). La Huella de Ruperta. Revista ITEA, Vol. 94A, 3:316-324

Rodrigañez, J., Toro, M., Rodríguez, C., \& Silió, L. (1998b). Supervivencia de alelos de estirpes portuguesas y españolas en una población de cerdos Ibéricos. IV Congresso Internacional do Porco Mediterrânico, 26,17 e 28 de Novembro, Universidade de Évora, Évora, pp.1-3

Ruiz, M., \& Herrero, A. (2015). La era de las ciencias ómicas. Edita Colegio Oficial de Farmacéuticos de Aragón. Academia de Farmacia "Reino de Aragón” Zaragoza, 63 pp.

Sancho, S., Casas, I., Ekwall, H., Saravia, F., Rodriguez-Martinez, H., Rodriguez-Gil, J., Flores, E., Pinart, E., Briz, M., Garcia-Gil, N., Bassols, J., Pruneda, A., Bussalleu, E., Yeste, M., \& Bonet, S., (2007). Effects of cryopreservation on semen quality and the expression of sperm membrane hexose transporters in the spermatozoa of Iberian pigs. Reproduction. 2007 Jul; 134(1):111-21. PMID: 17641093 DOI: 10.1530/REP-07-0118

Simões, A. (1964). A cria industrial do do porco cruzado de tipo carne. Edição da Junta Nacional dos Produtos Pecuários, Lisboa, 25 pp

Sanson, A. (1901). Traité de Zootéchnie. 11 Paris.

Zasiadczyk, L., Fraser, L., Kordan, W., \& Wasilewska, K. (2015). Individual and seasonal variations in the quality of fractionated boar ejaculates.Theriogenology, 2015 May; 83(8):1287-303. Doi: 10.1016/j.Theriogenology.2015.01.015. Epub 2015 Jan 21. 